\title{
Proactive construction safety systems and the human factor
}

Perry Forsythe BBuild, PhD

Professor of Construction Management, School of the Built Environment,

University of Technology Sydney, New South Wales, Australia

The paper undertakes an extensive and critical review of published works concerning the state of the art in safety systems based on building information modelling (BIM). It finds that despite considerable developmental work, much of the focus has been on the design and planning stages of projects. A gap still exists during the construction stage due to the unexpected dynamics that occur on site and the way that responsive human behaviour is not always predictable or rational. Modern proactive safety systems offer advanced real-time tracking of workers on site, which can be concurrently mapped onto a BIM model of the progressive construction. Such technology aims to provide realtime audio warnings to individual workers if they wander too close to hazards. However, the review raises new and under-explored challenges concerning the human factor - especially the way workers interact with such technology. Evidence from other industries suggests that possible areas of concern include mistrust in warnings, ignoring warnings, over-reliance on technology and 'the boy who cried wolf' syndrome. Poor ergonomic design may lead to the technology being under-utilised. An ongoing agenda for behavioural testing is recommended to assist further development.

\section{Introduction}

The construction industry is one of the largest sources of employment in most developed countries around the world, but unfortunately there is still room for improvement concerning worker safety. In 2005, the International Labour Organisation estimated that 60000 fatal accidents occur each year on construction sites around the world (ILO, 2005). Even in advanced economies this still remains an issue. For instance even though countries such as the UK and Australia have kept fatalities relatively low in recent years - the UK had an average of $2 \cdot 3$ per 100000 workers over the period 2008-2009 to 2012 2013 and Australia had an average of $4 \cdot 34$ per 100000 workers over the period 2007-2008 to 2011-2012 - the figures are still at least twice the average for manufacturing in the respective countries (Health and Safety Executive, 2013; Safe Work Australia, 2013). Worse, there were $8 \cdot 1$ reported construction worker fatalities per 100000 in Singapore in 2009 (Teoh, 2011), 9.5 per 100000 in Europe in 2006 (Eurostat, 2012) and 11 per 100000 in the USA in 2007 (LABORSTA, 2012). In terms of policy significance, the EU stated that 'Health and safety at work is now one of the most important and most highly developed aspects of EU policy on employment and social affairs' (Commission of the European Communities, 2007: p. 2).

In rank order and using Australian data from 2009-2010 as a basis for comment (Safe Work Australia, 2012), the construction industry was the third highest cause of work-related fatalities. In delving deeper into the causes of construction fatalities from related data (Safe Work Australia, 2013), it can be said that the main proportional causes of these fatalities in Australia between 2007-2008 and 2011-2012, were

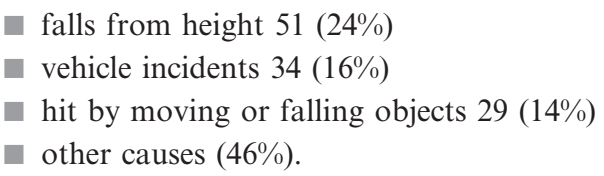

Similar causes and rankings can be seen in many countries spanning from the USA (Wu et al., 2013b) to locations in Asia, such as Taiwan (Chi et al., 2005).

Responsive action can be seen in the UK's study into the underlying causes of fatal accidents in construction and the subsequent 'combined model of accident causation' (Health and Safety Executive, 2009a, 2009b). Even so, it would seem that a number of the root causes of accidents have been known about for some time including things such as lack of attention to safety management, insufficient safety training, inadequate levels of physical safety on site, tiredness of workers, poor quality materials and equipment, and lack of attention to personal protection equipment (Cheng et al., 2004). Despite knowing about these issues, it would seem from the above statistics that new approaches are needed to improving safety on site. Hence, the focus of this paper is on the state of the art in building information modelling (BIM)-based safety technology - but with care taken to ensure that the main aim remains on 
technology for human safety sake, as opposed to technology for its own sake.

In this context, BIM is defined as the 'modelling technology and associated processes to produce, communicate, and analyse building models' (Eastman et al., 2011: p. 16). In more fully understanding the breadth of BIM technology, the diagrammatic representation (Figure 1) of Li et al. (2008) is instructive in showing the progression from basic three-dimensional (3D) modelling to more advanced virtual prototyping. For instance, a static 3D model authored using the likes of REVIT software (Autodesk, 2014) allows users a greater sense of spatial reality than is achievable under two-dimensional documentation; the model is made up of intelligent $3 \mathrm{D}$ objects thus enhancing the ability to analyse the buildability, functionality and aesthetics of a given project. The next stage in Figure 1 adds resourcing information including labour, plant and temporary work requirements, so that the construction team can plan and propose how best to undertake the intended processes on site, or to check progress. The third stage adds computer-based simulation and the ability to animate these processes on-screen (examples are shown in Figure 2). By adding motion, it facilitates the ability to detect problems and improve on intended work sequences. For the purposes of this paper, this stage is considered to be most consistent with the term 'four-dimensional (4D) modelling' - it allows users contextually to display construction on site at any point in time throughout the project. The final stage of Figure 1 augments this further by encompassing other participants such as subcontractors and field crews who may benefit from visualisation of intended work schedules.

Despite the benefits of presenting this BIM adoption structure, it is notable that the progression only goes as far as portraying

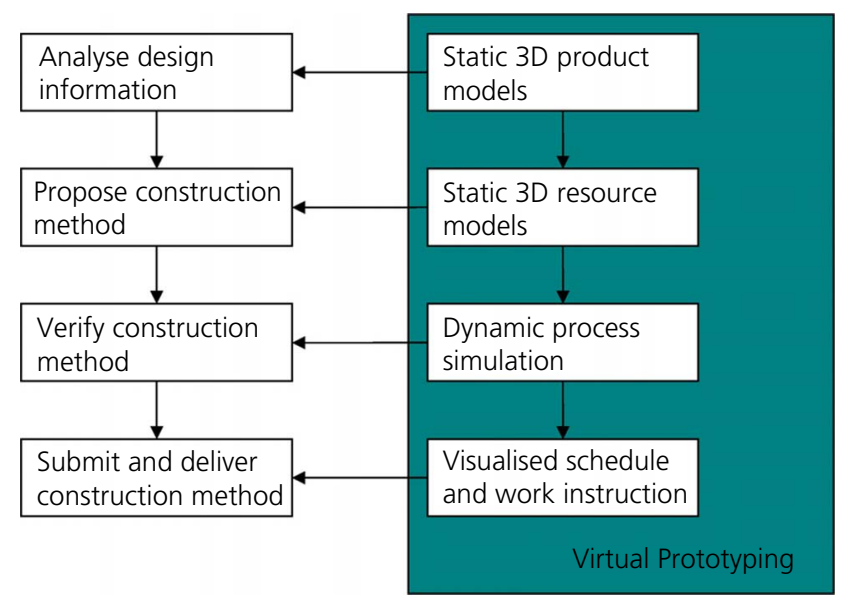

Figure 1. Excerpt from Li et al. (2008: p. 917) describing BIM usage from basic design analysis to virtual prototyping

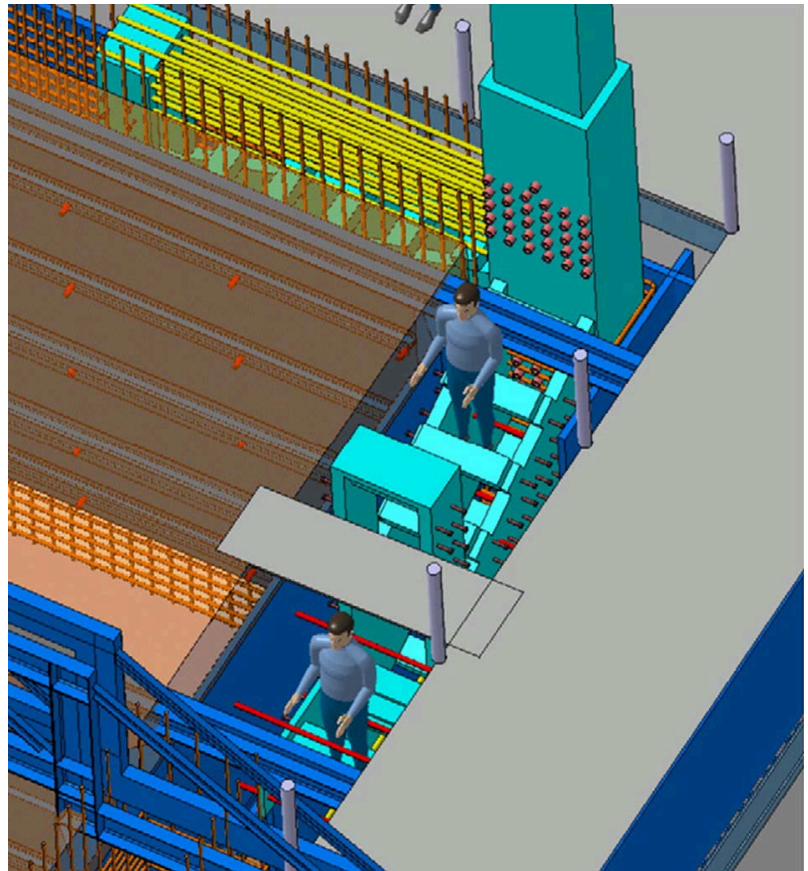

Figure 2. Excerpt from Li et al. (Li et al. 2008: p. 921) showing BIM 4D simulation

applications in the design and pre-construction planning stages of a project. A yet to be presented stage is the physical act of on-site construction. This is proposed as representing the next frontier in development - thus making it a step beyond current BIM uptake and the main ongoing focus of this paper.

Here, the relatively new ingredient is the addition of real-time locating technology, which can be used to determine where workers and objects are on site at any point in time. BIM technology is then used as the backdrop for tracking and mapping worker movements relative to safety risk hazards. In a combined sense, this creates a proactive approach because workers can be warned far more dynamically about hazards on site.

In the case of construction workers, there is the potential for movement sensors to be housed in their existing personal protection equipment, such as inside a safety helmet. The same technology can be used to create virtual safety fences on site or to monitor the location of moving objects and site-based vehicles. The underlying objective is to provide immediate and real-time warnings to workers where they may be approaching a danger area or getting too close to cranes, vehicles and other moving equipment. Importantly, the model must depict the progressive construction on site rather than the completed building, and so it must include things like temporary works, false-work, site works, materials handling equipment, and other features required during the construction process (as shown in Figure 2). 
In such instances, video gaming technology may be used to merge real-time locating technology and 3D modelling technology to enhance the visualisation and usability of the merged data - see for example developments at the Construction Virtual Prototyping Lab at Hong Kong Polytechnic University, where a video can viewed at http://www.youtube.com/watch? $\mathrm{v}=$ OMEgn0amzM0 (CVPL 2012). Such efforts demonstrate the difference between BIM in the context of proactive safety as distinct from the previously mentioned 4D process simulation (which is more suited to pre-construction planning situations).

Despite the significant potential offered by such technology, it is asserted here that to date there has been little testing in natural construction settings to determine how well it works when considered from a human behaviour perspective. Is it ergonomically useful and will it actually change and improve worker safety on site given the individual whims, variability and idiosyncrasies often inherent in human behaviour? Behavioural testing in the context of experimental psychology is thought to be important in not only serving to determine how well such technology works in terms of genuine safety outcomes, but would also help improve the design of such systems, thus accelerating the uptake of future implementation. With this in mind, the paper undertakes a critical review of the above issue by focusing on the following activities.

Trends in the use of BIM in construction safety - including attention to its usage in the design and planning stages of a project and its more recent applications to real-time construction on site.

- Specific attention to recent efforts in developing proactive construction safety systems.

- The identification of 'human factor' problems that have occurred in other industries, which demonstrate that proactive safety technologies have hidden glitches and require user-based refinement in order to provide the intended benefits.

- A proposed research agenda for testing and improving the real-time BIM safety system with the human factor in mind.

Each is handled under appropriate headings that follow.

\section{Trends in the use of BIM applications in construction safety}

As alluded to previously, much of the current thrust of BIM development relates to the planning and design phases of projects. There are a number of salient reasons why this may be the case. For instance, policies enacted by the EU and specifically directive 92/57/EEC (EC, 1992) place greater emphasis on the designer in construction safety decisions (Martínez Aires et al., 2010). Quantitative links have been made between designing for construction safety and construction site fatalities, and subsequently it makes sense to focus on addressing safety during design (Gambatese et al., 2008). Even so, there is still a significant need for collaboration and vigilance across the entire supply chain and so a multi-level risk assessment and prevention approach is required throughout the delivery process, as is apparent in the likes of the UK's construction (design and management) regulations (HMG, 2007). Risk assessment is the primary means by which hazard events are identified and managed. The typical approach is to estimate the probability of hazard occurrence, determine the associated risk and then provide responsive control measures (Carter and Smith, 2006). In operational terms, this is typically conveyed to those managing and undertaking the work by means of documented work method statements.

A number of key drivers underpin decision-making in this area. For instance, a behaviour-based approach is broadly seen as being important including techniques relating to performance measurement and participative goal setting by those involved in work processes (Lingard and Rowlinson, 1997). Tacit knowledge about different types of construction and associated processes provide an underlying ability to choose between generic physical approaches to safety systems. Following on from this, understanding the construction schedule is important because hazards can be identified in accordance with specific work packages and can be planned for in advance. Learning from past accidents allows better insight into how best to prevent problems in the future (Gambatese et al., 2005) - an obvious step from this is that database technology can be used to capture such knowledge and then intelligently extract it according to specific selection criteria. An example is the TotalSafety web database, which allows users to draw on a raft of corporate and industry expertise to identify safety issues and support decision-making (Carter and Smith, 2006).

Of course all of these approaches become of little use if hazards remain undetected (Carter and Smith, 2006). This is potentially where BIM can help. For instance, BIM improves the ability to analyse and interrogate both the $3 \mathrm{D}$ model of a building and its 4D manifestation. Although this may begin with the designer, the model can then be shared and improved on by parties progressively involved in the supply chain as long as the appropriate collaborative tools are available, and as long as the technology encourages awareness of problems as distinct from a state of technology-driven mindlessness (Zhou et al., 2012). Of note, there is the need to make sure that the more advanced proactive safety technology described previously serves actually to increase the ability of workers to recognise and perceive hazards in the workplace, otherwise behaviour-based safety becomes far less effective (Lingard and Rowlinson, 1997).

In optimising BIM in both the design and planning phases of a project, it is pertinent to point out that the overall approach relies on linking 3D capability with databases and knowledge 
bases that provide intelligent interpretation of the design (Aksamija et al., 2010). Early instances of this include the design-for-safety process, which utilises virtual reality and database technologies to help identify potential construction risks inherent in the design during construction (Hadikusumo and Rowlinson, 2002, 2004).

Progress has seen BIM increasingly used in the 4D safety planning of construction processes. Work at VTT (Finland) concerns 4D site layout whereby construction schedules have been linked with building elements, temporary structures and site production equipment (Sulankivi et al., 2010). The 4D phasing simulation has been coupled with $3 \mathrm{D}$ walk-throughs and $3 \mathrm{D}$ renderings, which have been used to identify hazards and communicate safety plans to site workers (Azhar and Behringer, 2013). In structural analysis, $\mathrm{Hu}$ and Zhang ( $\mathrm{Hu}$ and Zhang, 2011; Zhang and $\mathrm{Hu}, 2011$ ) proposed a new approach for conflict and safety analysis by integrating construction simulation, 4D construction management, and safety analysis leading to the introduction of the safety analysis of building in construction system.

Guo et al. (2013) go further in terms of their conceptual vision for adopting virtual prototyping technology in construction safety management by including components relating to modelling, simulation, the identification of unsafe factors and safety training. Similarly, research by Chun et al. (2012) explores the use of computer simulation techniques to create virtual environments in which users can explore and identify construction hazards. Here, virtual prototyping technology was deployed to develop typical construction scenarios in which unsafe or hazardous incidents occurred and user performance was evaluated based on responses to incidents within the virtual environment, whereas effectiveness was established through interviews with the safety project management team.

Bansal (2011) chose a different approach to merge technologies by combining geographic information system (GIS)-based navigable $3 \mathrm{D}$ animations and concurrently predicting places and activities where there was an increased likelihood of accidents. Along a similar line, Patrucco et al. (2010) aimed to augment the job safety analysis technique by using computer image generation to simulate and create animations of expected work situations on projects. Of note, they included the use of anthropometric parameters of human movement with the aim of achieving easier, faster and more intuitive consideration of potential hazards, thus helping risk analysis and remedial actions that could be implemented at the design and pre-construction stages of a project.

What can be said about all of the above instances is that there has been an emphasis on identifying hazards and then mitigating them through either the design or planning processes. All appear to be emerging technologies that are at a conceptual or prototyping stage and have yet to become commonplace in work environments. It is also clear that the more advanced applications are gradually gearing more and more towards 4Dstyle simulation and virtual prototyping. Even though some use real-time data, it is important to point out that they are still reactive technologies rather than proactive technologies. For instance, Teizer et al. (2010) make the point that reactive technology may collect data in real time, but must then undergo further processing and analysis to convert the data into useful information for management decision-making and other uses. In contrast, proactive technology collects data and provides real-time warning and immediate feedback to workers about dangers at that point in time. As mentioned, this is seen as a new frontier and so the following section explores the state of the art in this area of technology.

\section{The state of the art in proactive construction safety systems}

Whereas authors such as Szymberski (1997) propose that the ability to influence site safety is progressively reduced as the project moves into construction, there is a somewhat competing need to guard against over-planning if this comes at the cost of reduced real-time safey management. For instance, planning is by nature a predictive process but construction projects have a habit of changing during the real-time dynamics of work processes. The point here is simply that planners and planning processes utilise rational assumptions in order to develop the systematic responses discussed above. However, a part of the problem that is rarely mentioned is that human behaviour is at times irrational and therefore there is a greater need to expect the unexpected - hence the benefit of the proactive approach to safety management because it has the potential to deal more fully with the changing dynamics that occur in real time during work processes.

Despite being an emerging technology, there is still a significant body of research concerning the development of proactive construction safety systems. Many of the real-time tracking applications occur in excavation, civil and crane usage settings. These are perhaps obvious areas given the size of excavators, trucks and cranes - especially where safety is coupled with the inherent lack of clear viewing space for machine operators, the height that they sit above the work area and therefore the likelihood of accidents with unsuspecting site workers below. Instances of work in this area include that of Allread (2009), who focused on excavation equipment in civil construction settings and their use of radio frequency wave spectrum technology to alert workers in real time when they are in danger and where blind spots occur for machine operators. Li et al. (2013) studied cranage and blind-lifting scenarios whereby a real-time monitoring system integrating global positioning systems (GPS) and radio frequency identification (RFID) 
applied to a BIM environment was used to detect the interactive proximity between workers and the crane movement. For instance, when workers were too close to the crane, a warning was provided. Cheng and Teizer $(2012,2013)$ also focused on crane usage and enlisted a proactive approach to increasing crane operator awareness of workers at ground level. They used laser scanning to facilitate 3D modelling of the as-built conditions on site with real-time locating technology to determine dynamically the location of workers on the ground. Algorithms were developed to identify blind spots, tracking of workers and fusing of data to allow quantitative assessment of dynamically occuring situations. Similarly, Teizer et al. (2010) tested remote sensing and actuating technology to warn workers when too close to heavy construction equipment. Wu et al. (2013a) focused more on a real-time and location-based service approach for the prevention of large haulage equipment collisions involving concrete buckets during dam construction, whereby wireless communications, GPS, GIS technologies and algorithms were combined automatically to detect potential hazards and alert drivers accordingly.

An important issue effecting the viability of the abovementioned studies is the need for reliable and accurate tracking of people, equipment and objects. For instance, it is apparent when using GPS on a modern smart phone that it does not provide pinpoint accuracy and although this is not necessarily important in this application, locational acuracy may be the difference between life and death when applied to hazardous 'no go' zones on construction sites. The issues effecting accuracy and usability include the size of the site, the range of tracking equipment, the ability for signals to penetrate through walls and the extent of locational accuracy. Teizer et al. (2013) provide insight into such issues with their emphasis on ultra-wideband technology including its ability to provide $3 \mathrm{D}$ and 4D location values accurately in real time, and the ability to deal with indoor and outdoor settings. They also consider active RFID and the use of laser detection and range tracking technology.

In providing further background on field testing, Lee et al. (2009) established a prototype safety monitoring system that sensed worker locations and transmitted these to a receiver and dedicated software for interpretation. Of relevance to the ability ergonomically to track and provide feedback to workers is the work of Abderrahim et al. (2005), which involved developing a safety helmet for use in determining the position of workers on site. Using radio technologically, the identity of each worker was sampled periodically and the information was compared to a database containing the tasks and processes being performed, thus risk situations could be identified and acted on.

In merging a variety of technologies on large transit projects, Ding and Zhou (2013) developed a web-based safety system using field data (based on monitoring measurements, calculated predictions and visual inspections), which was used to imitate human expertise for safety risk assessment and automatic early warning of problems.

Yet another area of the proactive construction safety system approach concerns the algorithms and intelligence needed to understand digitally the nature of clashes between people with hazards. For instance, proactive systems need to forewarn people predictively before a clash actually occurs and so algorithms built around proximity and movement pathways are of relevance. Here, Kim et al. (2005) presented preliminary results of a human-assisted object avoidance system with a $3 \mathrm{D}$ work space model, suited to heavy equipment operations. McLaughlin et al. (2004) developed an automated obstacle avoidance system to allow safe operation of moving machines. Teizer et al. (2005) developed algorithms to process range information into meaningful 3D computer models, which improved the speed, predictability and safety of heavy equipment operation in construction processes - for both static and moving objects.

Other applications that present further variants on the above themes include the likes of work by Riaz et al. (2006), who produced a conceptual model of a proactive health and safety system called SightSafety. It tracks vehicles and equipment, and calculates whether workers are in danger zones by using a combination of GPS, smart sensors and wireless networks. It aims to prevent accidents by reporting on dangerous occurrences, thereby enabling managers to learn and undertake improved prevention.

Not all applications are purely site oriented. Teizer et al. (2013) present a novel approach for training steel erection workers using real-time location tracking and $3 \mathrm{D}$ immersive data visualisation technologies at an indoor training facility - their results indicate that unsafe practices in training environments can be detected and visualised and measured in assessment activities. Carbonari et al. (2011) developed a prototype system using USB real-time tracking technology for proactively alerting workers when approaching predefined hazard zones. Here, virtual fences were used to mark hazardous areas and the computer-based site layout plan allowed real-time visualisation of the tracked resources and signalling of potential hazards.

The above discussion provides an overview concerning the state of the art in proactive construction safety systems. The main examples of interest include those in which tracking of workers, vehicles and objects can be mapped onto a 3D BIM model that can be automatically analysed and provide immediate feedback directly to workers, where safety problems may occur. What can also be said as a generalisation about the above is threefold. 
- Much of the previously cited body of work focuses on the technology itself; that is, mainly the technical ability of such systems to function and perform both accurately and reliably.

- The majority of the work focuses on excavation, civil and infrastructure applications. Only a limited number of instances apply to building construction and mainly in the specific context of cranage as distinct from broader based building activities.

- The technology has yet to reach the stage of 'human factor' testing; that is, where there is an emphasis on how well the technology interfaces with and influences human safety behaviour on site.

It is the latter two areas that are of most interest to the ongoing discussion. For instance, building sites are far more cluttered than those of mining or open excavation sites. As buildings progress, there is less focus on open site vehicle movements, and instead a greater focus on complex dynamics in terms of the number of people on site, people movement, height issues, materials handling, temporary materials storage locations, and temporary works (e.g. scaffolding, formwork, material storage). For intsance, if one walks through the partially completed structure of a highrise building, what is most evident is the visual clutter, movement, and the fact that many separate things are happening at once. Hazards can therefore change in less obvious ways and workers have more sensory distractions in terms of both visual and experiential cues.

With regard to this, little in the construction management literature seems to exist about how the idealised benefits of proactive construction safety systems work in such chaotic settings. For instance, authors such as Cheng and Teizer (2013) speak of such technology as providing a back-up as distinct from a front-line approach, but sometimes parallel systems create their own problems because there is divided commitment and so neither works properly. Consequently, it seems that this technology must quickly progress to having a valid and appropriately synthesised place in front-line approaches to safety. There must be a clear strategy about how the technology will play a strong and fitting role, especially given its expensive price tag. Consequently, in order to help the proactive safety approach graduate to a front-line approach, it is considered that human factor testing is important as the next step in the progress of this technology.

\section{Dealing with the human factor: the next step forward}

In more fully explaining the so called 'human factor', it is simply used here to describe the way humans interact with technology and the extent to which technology provides desired user outcomes. It can be studied by means of experimental psychology - by observing natural behaviour when people are using such technology. For instance, not everyone has the same aptitude, inclination or range of usage when using the items such as a new smartphone - one need only look at the difference in the way a young person uses it compared to an older person to comprehend the difference.

As alluded to previously, one of the key issues in dealing with the human factor is simply the variability and irrational nature that sometimes befits their behaviour. As an example concerning safety in construction, Choudhry and Fang (2008) found that workers engage in unsafe behaviour by a lack of safety awareness, a macho culture, work pressure, co-workers' attitudes and other organisational, economic and psychological factors. It is hard to predict how and when such things may impact in the workplace. Looking more specifically at some of the underlying organisational factors linked with the building site environment, it is apparent that the following are common and yet hard to control in terms of impact on safety behaviour.

The transient and sub-contract nature of the workforce on projects.

- The number of people who do not speak English as their first language and the cultural diversity that often exists on building sites.

The variable worker population over the life of the project the people on site change regularly.

The differing nature of each project and the subsequent need for customised safety training and induction.

- The way the work environment and the object under production are the same thing, therefore the physical work environment changes daily - as does the safety environment until the end product is finally reached.

As mentioned previously, all such factors are not easily controlled by pre-construction planning alone, but must instead be managed as dynamic variables during construction. Existing efforts have tended to focus on enhancing safety management procedures, protective measures, signage, and providing safety training. While useful, it seems these methods on their own have reached a point of diminishing returns in dealing with dynamically occuring safety problems on site. Hence, there is the case for utilising the previously discussed proactive safety systems. One of the potential benefits of this technology is that it can provide individually based feedback that has the potential to be quickly and simply understood by a wide variety of users thus dealing with quite a few of the bullet point items mentioned above.

Of course, the great concern is that theoretical benefits may not be as easily realised in practice due to the variability of the aforementioned human factor. As an example, there is the potentially fundamental problem that over-reliance on warnings (provided automatically by proactive safety systems) may 
inadvertently encourage mindlessness among workers, hence reducing their own internal inclination to analyse safety problems (Zhou et al., 2012). There is also the 'cry wolf' syndrome (Bliss and Dunn, 2000) where a warning that goes off too often or inappropriately gradually becomes ignored. Along a similar vein of logic, Barnett et al. (1989) hypothesise that every safety system will give rise to a statistically significant pattern of user dependence, and that this may have both its pros and cons in terms of its implementation and eventual usefuleness to human activity in the workplace.

Authors such as Carter and Smith (2006) suggest that on construction projects hazard identification is often far from ideal, hence there is the chance that proactive safety systems may not hold a full and complete register of the hazards that actually exist. From this, workers could either develop a false sense of security, or alternatively total mistrust of the system. Adding to this problem, digital construction schedules are said to be rarely updated sufficiently to reflect exact operations at a given point in time (Zhou et al., 2012), thus reducing the potential for proactive safety systems to remain up to date about hazard locations.

As mentioned previously, the proactive system relies on a continually updated BIM of the progressive site in order to identify safety hazards. But an as yet unmentioned problem is the degree of detail to be provided in the BIM for dealing with such identification. When considering areas like back propping and falsework the situation concerning detail is similar to the old saying, 'you can't see the trees for the forest'. In continuing the analogy, it raises the question about whether you model the forest as a whole, or each tree individually? Either will give different levels of detail about safety hazards. The main problem here is the extent to which workers understand the way the system is working and consequently the extent of safety assistance it is providing. Under such circumstances, there is again the potential for a false sense of security or, for those who are more cynical, mistrust in the system.

\section{Research into safety and warning systems in other industries}

In searching for direction about how to manage and improve the human factor in proactive safety systems, guidance can be taken from ergonomic testing and accident investigation in other industries. For instance, from a user's perspective Laughery (2006) identified that warning systems need to be noticed, encoded and provide understandable information thus making situational warning design important. Bliss and Dunn (2000) investigated the effect of increasing a worker's primary task and alarm workload and how this impacts on alarm mistrust. Along a similar line, Bliss et al. (2007) examined how alarm duration influenced user reactions under varying alarm rates. Interestingly, they found that signal duration is important but task complexity may lead workers to adopt other reaction behaviours. In contrast, Carbonneau (2013) explored the adverse effects that hearing protection devices in industrial settings have on preventing individuals from hearing warning signals.

In vehicle collisions, Baldwin and May (2011) examined the impact of semantic and acoustics alarm parameters relating to warning systems and driver responses. They used a simulated vehicle encountering unexpected hazard events with different alarms. They tested signal words such as 'notice' or 'danger', which were presented at different sound levels and these treatments were found to be important in drivers' responsive behaviour.

It is also apparent that research in natural settings is important because it often exposes different safety behaviours compared to controlled environments (Tontsch et al., 2013). As a case in point, Wong and Huang (2013) studied glance-cycle data from car drivers in natural settings, and were able to measure directionally based lapses in driver awareness. Still further, research into car accidents and mobile phone usage surprisingly indicates that accidents often occur shortly after phone usage rather than during usage, which is somewhat counterintuitive to what one would expect to be the case.

Given the above points, a key issue is that humans often respond to technology differently to the way that was perhaps expected. Consequently in this research agenda, there is a need to know whether or not construction workers will actually respond as expected when assisted by proactive safety systems. Real-world testing should be preferred over controlled laboratory conditions. The issues that need to be investigated include the following questions.

In noisy and at times visually cluttered site environments, are there limits as to how well proactive safety systems assist the sensory perception of workers? This includes issues such as how well the real-time positioning apparatus warning by workers can be heard over construction noise, how it may clash with use of hearing protection equipment, how it may impede the use of other personal protection equipment.

Is there a clear response by workers when given an early warning and if so, what is their response time and is the responsive action in accordance with expected safety behaviour?

- Building sites contain large amounts of temporary works (e.g. scaffolding, formwork, stockpiled materials) thus creating physical and visual clutter. There is a need to know to what level of detail these and others objects should be modelled at, in 3D environments including 
- will high levels of detail help workers, or simply create information overload, a false sense of security or mistrust in the system?

- the higher the level of detail, the greater the work for BIM modellers - can these people sustain vigilance in keeping such models up to date and do they have the construction knowledge to attend to such detail?

Does the apparatus operate ergonomically, comfortably and practically from the perspective of a diverse demographic spectrum of workers. If not, will they remove it or turn it off rather than use it?

- Should the apparatus for tracking and feedback be used all the time for continuous service on site, or should it be used temporarily for training only? Of note, the former may suffer from the previous ergonomic issues; the latter relies on conditioning or shaping behaviour but must avoid static memory about the site itself as hazard locations will change with construction progress.

- Warning systems may be activated irregularly if targeting a limited range of high-risk safety hazards. As a result, will this create confusion or a slow response time among workers, due to the unfamiliar nature of the warning signal?

Conversely, if warning systems aim to cover a wide range of hazard types, will workers readily understand the specifics of the different warnings and respond accordingly, or will they become confused by virtue of having too many types of warning signals to deal with?

- Will the warning system suffer from 'the boy who cried wolf' syndrome whereby a warning that goes off too often or imparts obviously incorrect information begins to become ignored or distrusted by workers?

- To improve the quality and feature set of audible warning systems, would it be best to utilise stereophonic sound, which could help to indicate to the worker if an approaching hazard (such as a moving vehicle) is coming from their right, left, front, or back?

- To what extent will workers remove or turn off the apparatus due to the conviction that it breaches their privacy and because they do not want to be tracked?

- To what extent will workers behave naturally if they know they are being tracked (i.e. due to a 'big brother' effect)? What are the positive and negative connotations of this from a safety perspective?

In addressing these issues, it is considered best to use the previously mentioned experimental psychology approach, which focuses on objectively observing and recording behaviour by workers as they go about their daily routine on site. The ability to do this is to some extent already inherent in the proactive safety approach because workers are tracked and then mapped onto a BIM model, and so it is quite realistic to record this and make observations relative to their interaction with safety hazards after receiving a warning signal.

\section{Other considerations for decision-makers}

The above not only raises behavioural issues for those directly involved in work on site, but clearly more broad-based ethical and managerial issues as well. For instance, will an initial emphasis on worker safety simply become a façade for gathering data about other more financially driven objectives such as labour productivity? Do the true benefits of such a system outweigh the investment cost?

A more practical issue is simply whether or not it is realistic to keep the BIM appropriately up to date to the extent that it will accurately and reliably reflect the changing construction adequately to provide appropriate safety warnings. Finally, will the use of proactive safety systems create a new threshold regarding the legal duty of care for those implementing such systems, and consequently will it create significantly new responsibilities for project managers.

\section{Conclusion}

The study identifies that traditional approaches to construction safety may have reached a threshold point in terms of the ability to provide significantly higher safety outcomes for workers. BIM-based applications are proposed as providing new potential but on the condition that the focus be on behaviourally based benefits and on technology for safety sake, as distinct from technology for its own sake.

The analysis demonstrates that most of the BIM development in safety to date has been on 3D and 4D applications - the majority of which focuses on the design and pre-planning phases of construction projects. In these cases, worker behaviour is an issue dealt with at arms length because safety measures are predictive and typically draw on the likes of knowledge bases (intelligently connected to BIM) to identify hazards that may occur on site. Despite the benefits that these applications bring, there is still a gap when it comes to worker safety on site unexpected dynamics occur and human behaviour is not always predictable or rational. Promising frontier technology described in the paper focuses specifically in this area. Here, BIM is merged with real-time locating technology to provide proactive safety systems. Worker movements are mapped onto the BIM, which contains the location of identified hazards and so direct and dynamic warnings can be provided to individual workers, by means of items such as audio equipment housed in the worker's safety helmet. The review shows that to date, the majority of research into this frontier technology has focused on the prototyping, hard science and functional performance of the system. However, the nature of real-time feedback creates new challenges concerning the 'human factor' - especially the way workers respond to dynamic safety warnings as they move about the site and whether it actually helps them respond to, and avoid, safety hazards. 
Evidence from other industries suggests that the technology must be ergonomically refined to suit the natural behaviour limitations of people as they go about their normal routines. If this is not incorporated into the technology then it may not provide its intended benefits. Given this, it is concluded that the way workers interact with proactive safety systems may not be as obvious as expected including the potential for mistrust in warnings, ignoring warnings and over-reliance on technology. Poor ergonomic design may lead to the technology being unused or discarded.

It is concluded that to help the technology move beyond a prototyping stage and be deemed appropriate for real-world use, human factor testing is important. Subsequently, an agenda of research questions has been identified. Some specific problems include whether or not warnings from proactive safety systems help or hinder workers' sensory perception of safety hazards; confirmation of the extent to which warnings actually cause responsive action by workers; understanding whether or not workers become confused by warning signals and if such signals suffer from 'the boy who cried wolf' syndrome when warnings go off too regularly or impart obviously inaccurate information.

The emphasis of ongong research should be on a transdisciplinary approach that includes an amalgam of experimental psychology, ergonomic psychology, construction process management and behaviour-based safety management expertise. Attention should be on observing and recording human acceptance of the technology in daily workplace situations. The fact that the proactive safety approach maps workers' movements onto a BIM should assist in the recording of data and the ability to make relatively objective observations from them.

\section{REFERENCES}

Abderrahim M, Garcia E, Diez R and Balaguer C (2005) A mechatronics security system for the construction site. Automation in Construction 14(4): 460-466.

Aksamija A, Yu K, Kim H, Grobler F and Krishnamurti R (2010) Integration of knowledge-based and generative systems for building characterization and prediction. Artificial Intelligence for Engineering Design, Analysis and Manufacturing: AI EDAM 24(1): 3.

Allread BS (2009) Real-time Pro-active Safety in Construction. Masters thesis, Georgia Institute of Technology, Atlanta, GA, USA.

Azhar S and Behringer A (2013) A BIM-based approach for communicating and implementing a construction site safety plan. Proceedings of the 49th ASC Annual International Conference, California Polytechnic State University, San Luis Obispo, CA, USA.

Autodesk (2014) http://www.autodesk.com/products/revitfamily/overview (access 03/09/2014).
Baldwin CL and May JF (2011) Loudness interacts with semantics in auditory warnings to impact rear-end collisions. Transportation Research Part F: Traffic Psychology and Behaviour 14(1): 36-42.

Bansal V (2011) Application of geographic information systems in construction safety planning. International Journal of Project Management 29(1): 66-77.

Barnett RL, Barroso P, Hamilton BA and Litwin GD (1989) Selected principles of human safety in the workplace. International Journal of Materials and Product Technology 4(2): 125-144.

Bliss JP and Dunn MC (2000) Behavioural implications of alarm mistrust as a function of task workload. Ergonomics 43(9): 1283-1300

Bliss JP, Fallon CK and Nica N (2007) The role of alarm signal duration as a cue for alarm validity. Applied Ergonomics 38(2): 191-199.

Carbonari A, Giretti A and Naticchia B (2011) A proactive system for real-time safety management in construction sites. Automation in Construction 20(6): 686-698.

Carbonneau M-A, Lezzoum N, Voix J and Gagnon G (2013) Detection of alarms and warning signals on an digital inear device. International Journal of Industrial Ergonomics 43(6): 503-511.

Carter G and Smith SD (2006) Safety hazard identification on construction projects. Journal of Construction Engineering and Management 132(2): 197-205.

Cheng E, Li H, Love P and Zahir I (2004) A learning culture for strategic partnering in construction. Construction Innovation 4(1): 53-65.

Cheng T and Teizer J (2012) Modeling tower crane operator visibility to minimize the risk of limited situational awareness. Journal of Computing in Civil Engineering 28(3): 401-404.

Cheng T and Teizer J (2013) Real-time resource location data collection and visualization technology for construction safety and activity monitoring applications. Automation in Construction 34: 3-15.

Chi C-F, Chang T-C and Ting H-I (2005) Accident patterns and prevention measures for fatal occupational falls in the construction industry. Applied Ergonomics 36(4): 391-400.

Choudhry RM and Fang D (2008) Why operatives engage in unsafe work behavior: investigating factors on construction sites. Safety Science 46(4): 566-584.

Chun CK, Li H and Skitmore M (2012) The use of virtual prototyping for hazard identification in the early design stage. Construction Innovation: Information, Process, Management 12(1): 29-42.

Commission of the European Communities (2007) Improving Quality and Productivity at Work: Community Strategy 2007 2012 on Health and Safety at Work. Commission of the European Communities, Brussels, Belgium. See http://eur-lex. europa.eu/LexUriServ/LexUriServ.do?uri=COM:2007:0062: FIN:EN:PDF (accessed 14/11/2013). 
CVPL (Construction Virtual Prototyping Laboratory) (2012) Proactive Construction Management System. Construction Virtual Prototyping Laboratory Hong Kong Polythechnic, Hong Kong. See http://www.youtube.com/ watch?v=OMEgn0amzM0 (accessed 27/06/2013).

Ding L and Zhou C (2013) Development of web-based system for safety risk early warning in urban metro construction. Automation in Construction 34: 45-55.

Eastman C, Teicholz P, Sacks R and Liston K (2011) BIM Handbook: A Guide to Building Information Modeling for Owners, Managers, Designers, Engineers and Contractors. Wiley, Hoboken, NJ, USA.

EC (European Community) Council Directive 92/57/EEC of 24 June 1992 on the implementation of minimum safety and health requirements at temporary or mobile construction sites (eighth individual Directive within the meaning of Article 16 (1) of Directive 89/391/EEC). Official Journal of the European Communities L245/6.

Eurostat (2012) The Statistical Office of the European Communities. European Commission, Brussels, Belgium. See http://epp.eurostat.ec.europa.eu/ (accessed 15/11/2013).

Gambatese JA, Behm M and Hinze JW (2005) Viability of designing for construction worker safety. Journal of Construction Engineering and Management 131(9): 1029-1236.

Gambatese JA, Behm M and Rajendran S (2008) Design's role in construction accident causality and prevention: Perspectives from an expert panel. Safety Science 46(4): 675-691.

Guo H, Li H and Li V (2013) VP-based safety management in large-scale construction projects: a conceptual framework. Automation in Construction 34: 16-24.

Hadikusumo B and Rowlinson S (2002) Integration of virtually real construction model and design-for-safetyprocess database. Automation in Construction 11(5): 501-509.

Hadikusumo B and Rowlinson S (2004) Capturing safety knowledge using design-for-safety-process tool. Journal of Construction Engineering and Management 130(2): 281289.

Health and Safety Executive (2009a) Phase 1 Report: Underlying Causes of Construction Fatal Accidents - A Comprehensive Review of Recent Work to Consolidate and Summarise Existing Knowledge. Her Majesty's Stationery Office, London, UK.

Health and Safety Executive (2009b) Phase 2 Report: Underlying Causes of Construction Fatal Accidents - Review and Sample Analysis of Recent Construction Fatal Accidents. Her Majesty's Stationery Office, London, UK.

Health and Safety Executive (2013) Health and Safety in Construction in Great Britain, 2013. Health and Safety Executive, London, UK. See http://www.hse.gov.uk/ statistics/industry/construction/construction.pdf (accessed 15/11/2013).
HMG (Her Majesty's Government) (2007) Health and Safety. The Construction (Design and Management) Regulations 2007. The Stationery Office, London, UK, Statutory Instrument 2007 No. 320.

Hu Z and Zhang J (2011) BIM- and 4D-based integrated solution of analysis and management for conflicts and structural safety problems during construction: 2 . Development and site trials. Automation in Construction 20(2): 167-180.

ILO (International Labour Organization) (2005) Fact Sheet on Safety at Work. International Labour Organization, Geneva, Switzerland.

Kim C, Haas CT, Liapi KA et al. (2005) Rapid human-assisted, obstacle avoidance system using sparse range point clouds. In Engineering, Construction and Operations in Challenging Environments: Earth and Space (Malla RB and Maji A (eds)). American Society of Civil Engineers, New York, NY, USA, pp. 115-122.

LABORSTA (2012) LABORSTA: An International Labour Office Database on Labour Statistics. ILO Department of Statistic, Geneva, Switzerland. See http://laborsta.ilo.org/ (accessed 15/11/2013).

Laughery KR (2006) Safety communications: Warnings. Applied Ergonomics 37(4): 467-478.

Lee U-K, Kim J-H, Cho H and Kang K-I (2009) Development of a mobile safety monitoring system for construction sites. Automation in Construction 18(3): 258-264.

Li H, Chan G and Skitmore M (2013) Integrating real time positioning systems to improve blind lifting and loading crane operations. Construction Management and Economics 31(6): 596-605.

Li H, Huang T, Kong C et al. (2008) Integrating design and construction through virtual prototyping. Automation in Construction 17(8): 915-922.

Lingard H and Rowlinson S (1997) Behaviour-based safety management in Hong Kong's construction industry. Journal of Safety Research 28(4): 243-256.

McLaughlin J, Sreenivasan S, Haas C and Liapi K (2004) Rapid human-assisted creation of bounding models for obstacle avoidance in construction. Computer-Aided Civil and Infrastructure Engineering 19(1): 3-15.

Martínez Aires MD, Rubio Gámez MC and Gibb A (2010) Prevention through design: the effect of European directives on construction workplace accidents. Safety Science 48(2): 248-258.

Patrucco M, Bersano D, Cigna C and Fissore F (2010) Computer image generation for job simulation: an effective approach to occupational risk analysis. Safety Science 48(4): 508-516.

Riaz Z, Edwards D and Thorpe A (2006) SightSafety: a hybrid information and communication technology system for reducing vehicle/pedestrian collisions. Automation in Construction 15(6): 719-728. 
Safe Work Australia (2012) Work-related Traumatic Injury Fatalities 2009-2010. Creative Commons, Canberra, Australia.

Safe Work Australia (2013) Construction Fact Sheet. Safe Work Australia, Canberra, Australia.

Sulankivi K, Kahkonen K, Makela T and Kiviniemi M (2010) 4DBIM for construction safety planning. In W099-Special Track 18th CIB World Building Congress May 2010 Salford, UK.

Szymberski R (1997) Construction project safety planning. Tappi Journal 80(11): 69-74.

Teizer J, Kim C, Bosche F, Caldas C and Haas C (2005) Real-time $3 \mathrm{D}$ modeling for accelerated and safer construction using emerging technology. Proceedings of the 1st International Conference on Construction Engineering and Management, Seoul, Korea, pp. 539-543.

Teizer J, Allread BS, Fullerton CE and Hinze J (2010)

Autonomous pro-active real-time construction worker and equipment operator proximity safety alert system. Automation in Construction 19(5): 630-640.

Teizer J, Cheng T and Fang Y (2013) Location tracking and data visualization technology to advance construction ironworkers' education and training in safety and productivity. Automation in Construction 35: 53-68.

Teoh K (2011) WSH Approach on the Construction Sector in Singapore. International Labour Organization, Geneva, Switzerland. See http://www.ilo.org/wcmsp5/ groups/public/---ed_protect/---protrav/---safework/ documents/presentation/wcms_169573.pdf (accessed 13/01/ 2014).

Tontsch A, Valero-Mora PM and Pareja I (2013) Identifying critical incidents in naturalistic driving data: experiences from a promoting real life observation for gaining understanding of road user behaviour in Europe smallscale field trial. IET Intelligent Transport Systems 7(2): 198-202.

Wong J-T and Huang S-H (2013) Attention allocation patterns in naturalistic driving. Accident Analysis and Prevention 58(C): 140-147.

Wu H, Tao J, Li X et al. (2013a) A location based service approach for collision warning systems in concrete dam construction. Safety Science 51(1): 338-346.

Wu W, Yang H, Li Q and Chew D (2013b) An integrated information management model for proactive prevention of struck-by-falling-object accidents on construction sites. Automation in Construction 34: 67-74.

Zhang J and Hu Z (2011) BIM- and 4D-based integrated solution of analysis and management for conflicts and structural safety problems during construction: 1 . Principles and methodologies. Automation in Construction 20(2): 155-166.

Zhou W, Whyte J and Sacks R (2012) Construction safety and digital design: a review. Automation in Construction 22: $102-111$.

\footnotetext{
WHAT DO YOU THINK?

To discuss this paper, please email up to 500 words to the editor at journals@ice.org.uk. Your contribution will be forwarded to the author(s) for a reply and, if considered appropriate by the editorial panel, will be published as discussion in a future issue of the journal.

Proceedings journals rely entirely on contributions sent in by civil engineering professionals, academics and students. Papers should be 2000-5000 words long (briefing papers should be 1000-2000 words long), with adequate illustrations and references. You can submit your paper online via www.icevirtuallibrary.com/content/journals, where you will also find detailed author guidelines.
} 